Short Note

\title{
Loss of $v t x$ Genes after the First Subcultivation Step of Verocytotoxigenic Escherichia coli 0157 and Non-O157 during Isolation from Naturally Contaminated Fecal Samples
}

\author{
Maria-Adelheid Joris ${ }^{1}{ }^{*}$, Karen Verstraete ${ }^{2}$, Koen De Reu ${ }^{2}$ and Lieven De Zutter ${ }^{1}$ \\ 1 Ghent University, Faculty of Veterinary Medicine, Salisburylaan 133, 9820 Merelbeke, Belgium; \\ E-Mail: lieven.dezutter@ugent.be \\ 2 Institute for Agricultural and Fisheries Research, Technology and Food Science Unit, \\ Brusselsesteenweg 370, 9090 Melle, Belgium; \\ E-Mails: karen.verstraete@ilvo.vlaanderen.be (K.V.); koen.dereu@ilvo.vlaanderen.be (K.D.R.) \\ * Author to whom correspondence should be addressed; E-Mail: adelheid.joris@ugent.be; \\ Tel.: +32-9-264-73-42; Fax: +32-9-264-74-91.
}

Received: 12 April 2011; in revised form: 1 June 2011 / Accepted: 8 June 2011 /

Published: 20 June 2011

\begin{abstract}
Verocytotoxins VT1 and VT2, produced by Verocytotoxigenic Escherichia coli (VTEC), are encoded on temperate bacteriophages. Several studies reported the loss of the $v t x$ genes after multiple subcultivation steps or long preservation. The objective of this study was to determine if the loss of the verocytotoxin genes can already occur during the first subcultivation step. Consequently, the stability of the $v t x$ genes were tested in 40 isolates originating from $40 v t x$-positive fecal samples after the first subcultivation step following the isolation procedure. The loss occurred in 12 out of 40 strains tested and was rather rare among the $\mathrm{O} 157$ strains compared to the non-O157 strains. This is the first study demonstrating that the loss of the verocytotoxin genes can already occur after the first subcultivation step. This may lead to an underestimation of VTEC positive samples.
\end{abstract}

Keywords: Escherichia coli; VTEC; loss; vtx genes 


\section{Introduction}

Verocytotoxigenic Escherichia coli (VTEC), also referred to as Shiga toxin-producing E. coli (STEC), are zoonotic pathogens associated with a high variety of clinical outcomes such as diarrhea, hemorrhagic colitis (HC) and hemolytic uremic syndrome (HUS). Human infections are in most cases acquired through water or food directly or indirectly contaminated with cattle feces. The key virulence factors are the verocytotoxins. There are two main types, namely VT1 and VT2, which can be further divided into subtypes based on their sequence analysis. The nomenclature is not definite and new variants are constantly being described. These VT-encoding genes ( $v t x)$ are generally encoded by a heterogenous group of temperate lambdoid bacteriophages and are expressed when the lytic cycle is activated [1,2].

In a cross-sectional survey, both $v t x$-negative and $v t x$-positive strains belonging to the same serogroup were detected on two cattle herds [3]. The absence of $v t x$ genes in strains carrying eae and EHEC-hlyA is thought to occur by two hypotheses. First of all, the vtx-negative strains could arise from strains that had lost their vtx genes during subculturing as several studies reported the spontaneous loss of $v t x$ genes after multiple subcultivation steps [4-8]. Secondly, these $v t x$-negative strains could occur as inherently $v t x$-negative strain in the animal reservoir as such [9], designated as aEPEC.

Since several studies observed the loss after multiple subcultivation steps and long preservation times, this study was set up to determine (i) if the loss of $v t x$ genes can already occur after the first subcultivation step after isolation, (ii) the frequency of this spontaneous loss, and (iii) to evaluate the toxin-type and serogroup dependence.

\section{Materials and Methods}

Rectal fecal samples were taken from cattle known to be infected with VTEC O157 and/or non-O157, on 3 cattle farms, to study the spontaneous loss of $v t x$ genes after the first subcultivation step of suspected colonies.

\subsection{VTEC O157}

To isolate E. coli $\mathrm{O} 157$ from fecal samples, $225 \mathrm{~mL}$ of modified TSB, supplemented with $0.25 \mathrm{~mL}$ novobiocin was added to $25 \mathrm{~g}$ of feces. After incubation for $6 \mathrm{~h}$ at $42{ }^{\circ} \mathrm{C}$, immunomagnetic separation technique (IMS) using specific Dynabeads (Invitrogen, Paisley, UK) was performed according the manufacturer's recommendations. The resulting suspension was plated onto cefixime-tellurite sorbitol-MacConkey agar (Oxoid Ltd., London, UK) and incubated overnight at $42{ }^{\circ} \mathrm{C}$. From each sample one well isolated suspected colony was transferred to tryptone soy agar (Oxoid) and incubated for $24 \mathrm{~h}$ at $37{ }^{\circ} \mathrm{C}$. Subsequently, 10 colonies of each subculture on TSA were examined for the presence of virulence genes by a multiplex PCR, applying the primers for vtxl, eae and EHEC-hlyA described by Fagan et al. [10] and for vtx2 described by Paton [11]. One isolate from the subculture was further tested for agglutination with an E. coli O157 latex test kit (Oxoid) for serogroup O157 confirmation. 


\subsection{VTEC Non-O157}

For the isolation of EHEC non-O157, the isolation method described by Possé [12] was used. Briefly, a $25 \mathrm{~g}$ amount of each sample was enriched during $24 \mathrm{~h}$ at $42{ }^{\circ} \mathrm{C}$ in $225 \mathrm{~mL}$ tryptone soya broth (TSB) supplemented with $8 \mathrm{mg} \mathrm{L}^{-1}$ novobiocin, $16 \mathrm{mg} \mathrm{L}^{-1}$ vancomycin, $2 \mathrm{mg} \mathrm{L}^{-1}$ rifampicin, $1.5 \mathrm{~g} \mathrm{~L}^{-1}$ bile salts and $1.0 \mathrm{mg} \mathrm{L}^{-1}$ potassium tellurite. After 6 and $24 \mathrm{~h}$ of incubation, respectively, 100 and $10 \mu \mathrm{L}$ of the enrichment broth was plated onto the new differential agar medium for $\mathrm{O} 26$, O111, O103 and O145 [13]. Besides this direct plating, IMS was applied after $24 \mathrm{~h}$ on the enrichment broth. For the serogroups O26 and O103, Dynabeads (Invitrogen) were used, whereas for the serogroups $\mathrm{O} 111$ and O145, Captivate beads (Lab M, Lancs, UK) were applied. Afterwards, $100 \mu \mathrm{L}$ of the IMS suspension was also plated onto these differential agar media. From each sample, one well isolated colony with a suspected morphology was subcultured to trypton soy agar (TSA) (Oxoid). Subsequently, 10 colonies of each subculture on TSA were examined for the presence of virulence genes by a multiplex PCR, as described above. Subsequently serogroup-specific PCR was conducted for the serogroups O26, O103, O111 and O145 [14].

\section{Results and Discussion}

Enterohemorrhagic E. coli (EHEC) are a distinct class of VTEC, characterized by the presence of verocytotoxins, intimin and EHEC enterohemolysin. The key virulence determinants are the verocytotoxins 1 and 2 encoded on temperate bacteriophages. EHEC strains may convert to atypical enteropathogenic E. coli (aEPEC) strains by the loss of their $v t x$ genes after multiple subcultivation steps or long preservation. These potential genetic changes of the pathogens have to be taken into account when interpreting screening results for the public health concern of O157 and non-O157 E. coli. To our knowledge, this is the first study conducted to examine the frequency of the loss of $v t x$ genes after the first subcultivation step among O157 and non-O157 EHEC strains during the isolation from naturally contaminated bovine fecal samples, as other studies focused on multiple subcultivation steps and long-term preservation. In this survey, fecal samples were collected on three farms housing EHEC carrier animals. The stability of $v t x$ genes were tested in 40 positive fecal samples (20 O157 and 20 non-O157 samples) after the first subculturing step. Noteworthy, this subcultivation step is advisable and even obligatory by the ISO method 16654:2001 [15] for the detection of E. coli O157 from feed and food to ensure the purity of the strains to be characterized.

Table 1. Spontaneous loss of vtx genes after the first subcultivation step among EHEC O157 and non-O157 strains.

\begin{tabular}{cccccccc}
\hline \multirow{2}{*}{ Serogroup } & \multirow{2}{*}{$\mathbf{N}^{\circ}$ of Strains } & \multicolumn{2}{c}{ Vtx Genes } & & \multicolumn{3}{c}{ Spontaneous Loss of Vtx Genes } \\
& & Vtxl & Vtx 2 & & Vtxl & Vtx2 & Range (1-10) \\
\hline O157 & 20 & 20 & 20 & & 1 & 2 & $1-2$ \\
\hline Non-O157 & & & & & & \\
O26 & 3 & 3 & 1 & 2 & 0 & $2-3$ \\
O103 & 2 & 2 & 0 & 2 & 0 & $1-3$ \\
Non-Typed & 15 & 15 & 3 & 3 & 2 & $1-8$ \\
\hline Total & 40 & 40 & 24 & 8 & 4 & $1-8$ \\
\hline
\end{tabular}


All tested strains were eae and EHEC-HlyA positive. The loss of $v t x$ genes among O157 strains was rather rare compared to non-O157 strains, namely in 3 out of $20 \mathrm{O} 157$ strains compared to 9 out of 20 non-O157 strains. Regardless of the differences in the isolation procedures, the frequency of this curing within the $3 \mathrm{O} 157$ strains was rather rare (on average 1 out of 10), while for the 9 non-O157 strains, the rate of loss was higher (on average 4 out of 10 isolates). These findings are in agreement with Schmidt et al. [16] who observed that $v t x$ genes appear to be more stably maintained in 0157 strains than in non-O157. Because at least one colony still harbored vtxl and/or vtx2 after subcultivation, it can be hypothesized that the loss already occurred during growth on the differential media. Our data may be of importance in the screening of VTEC because these toxigenic organisms of public health concern can become non-toxigenic after subcultivation. The question remains how frequently the loss of $v t x$ genes already occurs in the intestine of cattle as Bielaszewska et al. [17] reported that an appreciable subset of patients suffering from HUS excreted EHEC that lost their $v t x$ genes. The latter showed a common phylogeny with the EHEC of the corresponding serotype and they belong to the same MLST clonal complexes. The importance of free vtx-encoding bacteriophages should be addressed with regard to their role as vectors for horizontal virulence gene transfer [18] in the animal reservoir as Cobbaut [19] reported the presence of inherently $v t x$-negative strains on $v t x$-positive cattle herds. Therefore, the role of VT-producing E. coli may be of a greater concern than was previously assumed if there can be an alternate conversion between aEPEC and EHEC strains.

\section{Conclusions}

Our results prove that a loss of vtx genes in $v t x$-positive isolates can already occur after the first subculturing step of VTEC isolated from naturally contaminated samples. Consequently, this may lead to an underestimation of VTEC in animals, food and humans. Therefore, we advise to test different colonies instead of a single colony from a subculture for the presence of vtx genes in order to avoid false negative results.

\section{Acknowledgments}

This research was funded by the Belgian Federal Public Service of Health, Food Chain Safety and Environment (Contract RT-07/8-FOODZOON).

\section{Conflict of Interest}

Authors declare no conflict of interest.

\section{References}

1. Herold, S.; Karch, H.; Schmidt, H. Shiga toxin-encoding bacteriophages-genomes in motion. Int. J. Med. Microbiol. 2004, 294, 115-121.

2. Allison, H.E. Stx-phages: Drivers and mediators of the evolution of STEC and STEC-like pathogens. Future Microbiol. 2007, 2, 165-174. 
3. Joris, M.A. Cross-sectional survey of EHEC on 12 cattle farms. Unpublished work, 2011.

4. Karch, H.; Meyer, T.; Russmann, H.; Heesemann, J. Frequent loss of Shiga-like toxin genes in clinical isolates of Escherichia coli upon subcultivation. Infect. Immun. 1992, 60, 3464-3467.

5. Feng, P.; Dey, M.; Abe, A.; Takeda, T. Isogenic strain of Escherichia coli O157: H7 that has lost both Shiga toxin 1 and 2 genes. Clin. Diagn. Lab. Immunol. 2001, 8, 711-717.

6. Yoh, M.; Bi. Z.; Kamei, A.; Yamaichi, Y.; Matsuyama, J.; Iida, T.; Honda, T. Loss of the VT2 Gene during Preservation of Enterohemorrhagic Escherichia coli at Room Temperature. Microbiol. Cul. Collect. 2002, 18, 5.

7. Brooks, H.J.; Bettelheim, K.A.; Todd, B.; Holdaway, M.D. Non-O157 Vero cytotoxin producing Escherichia coli: Aetiological agents of diarrhoea in children in Dunedin, New Zealand. Comp. Immunol. Microbiol. Inf. Dis. 1997, 20, 163-170.

8. Vaishnavi, C.; Kaur, S.; Beutin, L.; Krueger, U. Phenotypic and molecular characterization of clinically isolated Escherichia coli. Ind. J. Pathol. Microbiol. 2010, 53, 503-508.

9. Trabulsi, L.R.; Keller, R.; Tardelli, G.T.A. Typical and atypical enteropathogenic Escherichia coli. Emerg. Inf. Dis. 2002, 8, 508-513.

10. Fagan, P.K.; Hornitzky, M.A.; Bettelheim, K.A.; Djordjevic, S.P. Detection of shiga-like toxin (stx1 and stx2), intimin (eaeA), and enterohemorrhagic Escherichia coli (EHEC) hemolysin (EHEC hlyA) genes in animal feces by multiplex PCR. Appl. Environ. Microbiol. 1999, 65, 868-872.

11. Paton, A.W.; Paton, J.C. Detection and characterization of Shiga toxigenic Escherichia coli by using multiplex PCR assays for stx1, stx2, eaeA, enterohemorrhagic E. coli hlyA, rfbO111, and rfbO157. J. Clin. Microbiol. 1998, 36, 598-602.

12. Posse, B.; de Zutter, L.; Heyndrickx, M.; Herman, L. Quantitative isolation efficiency of O26, O103, O111, O145 and O157 STEC serotypes from artificially contaminated food and cattle faeces samples using a new isolation protocol. J. Appl. Microbiol. 2008, 105, 227-235.

13. Possé, B.; de Zutter, L.; Heyndrickx, M.; Herman, L. Novel differential and confirmation plating media for Shiga toxin-producing Escherichia coli serotypes O26, O103, O111, O145 and sorbitol-positive and -negative O157. FEMS Microbiol. Lett. 2008, 282, 124-131.

14. Possé, B.; de Zutter, L.; Heyndrickx, M.; Herman, L. Metabolic and genetic profiling of clinical O157 and non-O157 Shiga-toxin-producing Escherichia coli. Res. Microbiol. 2007, 158, 591-599.

15. ISO. Microbiological Methods, ISO 16654: Microbiology of Food and Animal Feeding Stuffs-Horizontal Method for the Detection of Escherichia coli O157, 1st ed.; International Organization for Standardization: Geneva, Switherland, 2001.

16. Schmidt, H.; Scheef, J.; Huppertz, H.I.; Frosch, M.; Karch, H. Escherichia coli O157:H7 and O157:H(-) strains that do not produce Shiga toxin: Phenotypic and genetic characterization of isolates associated with diarrhea and hemolytic-uremic syndrome. J. Clin. Microbiol. 1999, 37, 3491-3496.

17. Bielaszewska, M.; Kock, R.; Friedrich, A.W.; von Eiff, C.; Zimmerhackl, L.B.; Karch, H.; Mellmann, A. Shiga Toxin-Mediated Hemolytic Uremic Syndrome: Time to Change the Diagnostic Paradigm? PLoS One 2007, 2, e1024, doi:10.1371/journal.pone.000102417.

18. Schmidt, H. Shiga-toxin-converting bacteriophages. Res. Microbiol. 2001, 152, 687-695. 
19. Cobbaut, K.; Houf, K.; Buvens, G.; Habib, I.; de Zutter, L. Occurrence of non-sorbitol fermenting, verocytotoxin-lacking Escherichia coli $\mathrm{O} 157$ on cattle farms. Vet. Microbiol. 2009, 138, 174-178.

(C) 2011 by the authors; licensee MDPI, Basel, Switzerland. This article is an open access article distributed under the terms and conditions of the Creative Commons Attribution license (http://creativecommons.org/licenses/by/3.0/). 